
\title{
$\begin{array}{ll}\text { Research Square } & \begin{array}{l}\text { Preprints are preliminary reports that have not undergone peer review. } \\ \text { They should not be considered conclusive, used to inform clinical practice, } \\ \text { or referenced by the media as validated information. }\end{array}\end{array}$
}

\section{A Study of Prevalence and Factors Associated with Geriatric Impairment: Evidence from a Cross-Sectional Study in India}

\section{Shubham Kumar}

International Institute for Population Sciences

\section{Shekhar Chauhan}

International Institute for Population Sciences

Ratna Patel ( $\nabla$ ratnapatelbhu@gmail.com )

International Institute for Population Sciences

David Jean Simon

Pantheon Sorbonne university

\section{Research Article}

Keywords: Cognitive impairment, Hearing impairment, Physical impairment, Speech impairment, Vision impairment, India

Posted Date: July 19th, 2021

DOI: https://doi.org/10.21203/rs.3.rs-701470/v1

License: (c) (i) This work is licensed under a Creative Commons Attribution 4.0 International License. Read Full License 


\section{Abstract}

Background: Increasing life expectancy and declining fertility, resulting from improved healthcare systems worldwide, has resulted in a growing elderly population. The paradigm shift of the population towards the aged has tremendous health implications. Therefore, this study intends to examine the five domains of geriatric impairment: physical, cognitive, hearing, vision, and speech impairment.

Methods: The prevalence and factors associated with geriatric impairment were examined in this study by utilizing Longitudinal Ageing Study in India (LASI) wave-I data. Bivariate and binary logistic regression analyses were used as study tools.

Results: The study has demonstrated that higher age had a gradient of negative impact on the older adults, although for the unadjusted model. Results found that female elderly (OR=0.81; C.I. $0.68-0.97)$ and educated elderly likely $(\mathrm{OR}=0.57 ; \mathrm{C} . \mathrm{I} .=0.32-1.02)$ were less likely to report geriatric impairment than their respective counterparts.

Conclusion: There is a need to building partnerships to develop effective programs tackling impairment among the elderly. Launching programs that provide education for older adults to elicit potential health benefits may reduce impairment progression.

\section{Background:}

Increasing life expectancy and declining fertility, resulting from improved healthcare systems worldwide, has resulted in a growing elderly population [1]. In a recently released report, World Health Organization (WHO) stated that between 2015 and 2050, the proportion of the worlds' population would nearly double from 12 percent to 22 percent [2].

Furthermore, the report stated that in 2050, 80 percent of the older people would be living in low-and-middle-income countries [2]. In India, the elderly population had increased significantly from 24.71 million in 1961 to 43.98 million in 1981 and further to 104 million in 2011 [3]. By 2050, the elderly population is further expected to rise to 323 million, or 19 percent of the total population of India [4]. The paradigm shift of the population towards the aged has tremendous health implications [5], [6].

Physical and cognitive impairment among the elderly are widely discussed topics in the literature arena; somehow, the required attention has not been given to other important impairments, namely, hearing, vision, and speech. Age is one of the crucial determinants of health [7]. Elderly people not only have to deal with physical ageing but also with the complications of mental and social well-being, leading to geriatric impairment. Owing to the normal ageing of the brain, deteriorating physical health, and cerebral pathology, the overall geriatric impairment tends to increase with age [8]. Certain factors, including illnesses, chronic diseases, lack of family support, financial dependency, reduced mobility, depression, and severe Activity of Daily Living (ADL), and severe Instrumental Activity of Daily Living (IADL), are some of the contributory factors towards geriatric impairment [9]-[13].

Hearing and vision loss are two crucial sensory impairments in the elderly [14]. In contrast, mental issues among the elderly are associated with cognitive impairment [15]. Sensory impairment may augment existing problems due to cognitive impairment, thereby abbreviating the quality of life and functional ability among the elderly [16]. Furthermore, speech impairment is a language/communication impairment, which may also be sensitive to cognitive changes [17]. Physical and cognitive impairment are other important health issues among the elderly [18].

There is a growing recognition that the elderly population is more susceptible to chronic diseases [19], cognitive impairment [20], depression [21], poor mental health [22], psychological and subjective well-being [23], and reduced activity of daily living [24]. However, limited literature is available examining various geriatric impairments in the Indian 
context including, hearing impairment [25], vision impairment [26], [27], and speech impairment [28]. Few studies have examined physical and cognitive impairment among the elderly in India, but most of them were community-specific studies [29], [30]. Therefore, this study intends to examine the five domains of geriatric impairment: physical, cognitive, hearing, vision, and speech impairment. The prevalence and factors associated with geriatric impairment were examined in this study by utilizing recently released Longitudinal Ageing Study in India (LASI) wave-I data.

\section{Methods:}

\section{Data:}

The Longitudinal Ageing Study in India (LASI) is a multidisciplinary, internationally recognized panel study of 45 and above, conducted in all 35 states (except Sikkim) and union territories in India. LASI provides comprehensive information on the critical economic, social, and health characteristics of the elderly in India. LASI is the world's most extensive and India's first longitudinal study, which was carried out for the elderly population.

The LASI survey instruments consist of the household schedule, individual schedule, biomarker, and community schedule. The household schedule comprises a key informant in each household and an individual and biomarker schedule administered to each selected respondent.

The LASI adopted a multistage stratified area cluster sampling design to select the representative sample. The survey has adopted a three-stage sampling design for rural areas and four stages for the urban area within each state. The first stage included the primary sampling unit (PSU), sub-district (Tehsils/Talukas) in each state/UTs. The second stage included the selection of villages in rural areas and wards in rural areas urban area. In the third stage, the selection of household was made in rural areas; however, an additional stage was added in urban areas. In urban areas, census enumeration blocks (CEBs) were randomly selected in each urban ward. In the fourth and final stage of the sampling, households were selected in each CEB.

The survey covered a panel sample of 72,250 population aged 45 years and above and their spouses, including 31,464 elderly aged 60 years and above and 6,749 oldest persons aged 75 years and above. Our study is concerned with 60 years and above population.

The survey followed three primary instruments to cover the estimated sample as Household survey schedule, individual survey schedule, and community survey schedule. The household survey schedule was carried out to one per household to all consenting randomly, collecting information on household roster, housing and environment, household consumption, household assets and debts, household income, and household health in insurance. Individual survey schedule was administered to each consenting respondent aged 45 years and above, including their eligible spouses. The individual was prepared to collect comprehensive information on demography, the work retirement and pension module, overall health and specific chronic diseases, mental health module, utilization of healthcare services, the family and social networks, the social welfare scheme module, the experimental module, and biomarkers. In last, the community schedule collected information on population characteristics, infrastructure and common resources, the accessibility and availability of healthcare services, and the coverage of health and social welfare programmes.

\section{Geriatric impairment}


Ageing is known as many physical and emotional changes that can affect the level of function and well-being of the elderly. These changes can lead to impairment among the elderly, subject to a multidimensional assessment to evaluate functional ability, physical health, cognition, mental health, hearing, visual, speech, and socioenvironmental circumstances. Physical or functional impairment includes upper or lower limb loss or impairment, manual dexterity, and impairment in coordination with different body organs. Mental and cognition impairment, also known as instinctual impairment, occurred when a person has certain cognitive functions, limitations, and skills like communication, learning, self-help, and social skills. Visual impairment can be defined as the problems in functions of the visual system, and hearing impairment consider hearing loss that prevents an individual from partial or total receiving sounds through the ear. Speech impairment refers to an inability to produce sounds or verbal communications.

\section{Study Variables:}

\section{Outcome variable}

The study considered geriatric impairment as an outcome variable which was divided into five categories like Physical impairment such as lower body or upper body, cognitive impairment such as intellectual, cognition, or learning impairment, Hearing impairment, Visual impairment; and Speech impairment such as speech production and language comprehension. All the impairment was self-reported as responses were observed in multiple forms. Further, geriatric impairments have been divided into the number of impairments $(0,1,2$, and $\geq 3)$ to understand the association between impairments and socio-economic and health characteristics. Further, geriatric impairment was categorized in binary form as "yes" and "no" to assess the likelihood of impairment by socio-demographic and health factors.

\section{Predictors:}

The predictors for this study are age (60-69 and 70 years and above); sex (male and female), marital status (currently married, never married, Divorced/Separated/Deserted/Widowhood), education (No education, below primary, primary, secondary, and higher); place of residence (rural and urban); living arrangements (living alone, with spouse and with others); currently working (yes and no); wealth index (poorest, poorer, middle, richer and richest); and self-rated health (poor and good). Further, activities of daily living (ADL) impairment was achieved from five indicators, namely bathing, dressing, mobility, feeding, and toileting. The instrumental activities of daily living (IADL) impairment scale was achieved from seven instrumental activities: preparing a hot meal (cooking and serving), shopping for groceries, making telephone calls, taking medications, doing work around the house or garden, managing money, such as paying bills and keeping track of expenses and getting around or finding an address in an unfamiliar place. Both the ADL and IADL impairment was categorized into the three categories as "severe," "moderate," and "no impairment" based on the scale given in previous studies [31], [32].

\section{Statistical analysis:}

For the deceptive purpose, we have compared socio-demographic and health characteristics between elderly with physical, cognitive, hearing, visual, and speech impairment to check the proportion of geriatric impairment. Again, we have compared socio-demographic and health characteristics with $0,1,2$, and 3 or more geriatric impairment among older persons. To assess the association between any geriatric impairment with socio-demographic and health 
characterizes, we used binary logistic regression with unadjusted and adjusted odds ratio as the formula is given below,

$$
\log (\text { odds })=\operatorname{logit}(p)=\ln \left(\frac{1}{1-p}\right)
$$

$$
\operatorname{logit}(p)=a+b 1 \times 1+b 2 \times 2+b 3 \times 3+\cdots b_{k} x_{k}+\varepsilon
$$

Where, $p$ is the probability of success, $a$ is the intercept, $b$ is the regression coefficient, and $\varepsilon$ is the random error.

\section{Results:}

Figure 1 depicts the prevalence of various geriatric impairments. Around 6.4 percent of the elderly reported physical impairment, 2.7 percent reported cognitive impairment, 0.9 percent reported hearing impairment, 0.4 percent reported visual impairment, and only 0.1 percent reported speech impairment.

Table 1 depicts the prevalence of geriatric impairment by selected socioeconomic and health characteristics. Results found that the geriatric impairments were higher among elderly aged 70+ than elderly aged 60-69 years; around 7.5 percent of elderly aged 70+ reported physical impairment whereas, only 5.6 percent of elderly aged 60-69 years reported physical impairment. Physical impairments were higher among male elderly $(6.8 \%$ vs. $6 \%)$ than in female elderly; however, a higher percentage of female reported cognitive impairment ( $2.8 \%$ vs. $2.4 \%$ ), Hearing impairment $(0.9 \%$ vs. $0.8 \%)$, and visual impairment ( $0.5 \%$ vs. $0.3 \%)$ than their male counterparts. Prevalence of all the impairment was higher among never-married elderly than their married counterparts. Furthermore, the prevalence of physical and cognitive impairment was higher among uneducated elderly, rural elderly, living alone elderly, elderly not working currently, elderly with poor self-rated health, and severe ADL and IADL. 
Table 1

Prevalence of geriatric impairments by selected socio-economic and health characteristics in India

\begin{tabular}{|c|c|c|c|c|}
\hline ent & $\begin{array}{l}\text { tal } \\
\text { iirment }\end{array}$ & $\begin{array}{l}\text { Hearing } \\
\text { impairment }\end{array}$ & $\begin{array}{l}\text { Visual } \\
\text { impairment }\end{array}$ & ech \\
\hline
\end{tabular}

Age

$60-69$

5.6

2.4

0.6

0.3

0.0

18,410

$70+$

7.5

3.0

1.2

0.6

0.2

13,054

Sex

Male

6.8

2.4

0.8

0.3

0.1

14,931

Female

6.0

2.8

0.9

0.5

0.1

16,533

\section{Marital Status}

Currently married

5.8

2.4

0.7

0.3

0.1

19,536

Never Married

19.9

3.8

1.1

0.8

0.5

225

Divorced/Separated/Deserted

7.1

3.0

1.1

0.5

0.2

11,703

\section{Education}

No education

7.0

3.1

0.9

0.4

0.2

17,782

Below primary

6.5

2.7

1.0

0.8

0.1

3,598

Primary

6.8

2.3

1.0

0.4

0.0

3,520

Secondary

4.7

1.5

0.8

0.2

0.0

5,285

Higher

2.9

2.1

0.4

0.1

0.2

1,278

\section{Place of residence}

Rura

Urban

6.4

3.0

0.9

0.5

0.1

22,196

Urban

6.3

1.9

0.7

0.2

0.1

9,268

\section{Living arrangements}

Living alone

8.5

3.2

0.9

0.2

0.1

1,787

With spouse

5.8

2.4

0.7

0.2

0.1

19,176

With others

7.1

2.9

1.1

0.8

0.2

10,501

\section{Currently working}

Yes

4.7

2.2

0.6

0.1

0.0

9,483

No

7.7

3.1

1.0

0.6

0.1

13,197

Wealth Index

Poorest

7.1

2.6

0.8

0.2

0.1

6,829

Poorer

6.6

3.1

0.8

0.5

0.1

6,831 


\begin{tabular}{lllllll} 
Middle & 5.8 & 2.3 & 1.2 & 0.3 & 0.2 & 6,590 \\
\hline Richer & 6.5 & 2.5 & 0.7 & 0.6 & 0.1 & 6,038 \\
\hline Richest & 5.7 & 2.8 & 0.9 & 0.4 & 0.1 & 5,175
\end{tabular}

\section{Self-rated health}

\begin{tabular}{lllllll} 
Poor & 9.8 & 4.8 & 1.9 & 0.6 & 0.3 & 4,630 \\
\hline Good & 5.4 & 2.0 & 0.6 & 0.1 & 0.0 & 26,181 \\
\hline
\end{tabular}

\section{ADL disability}

\begin{tabular}{lllllll} 
Severe ADL & 15.6 & 9.6 & 2.9 & 2.8 & 1.4 & 999 \\
\hline Moderate ADL & 10.4 & 4.4 & 1.6 & 0.7 & 0.2 & 6,045 \\
\hline No ADL & 5.1 & 2.0 & 0.6 & 0.2 & 0.0 & 24,291 \\
\hline
\end{tabular}

\section{IADL disability}

\begin{tabular}{lllllll}
\hline Severe IADL & 13.6 & 7.6 & 2.9 & 2.7 & 1.4 & 1,859 \\
\hline Moderate IADL & 7.7 & 3.2 & 1.2 & 0.5 & 0.0 & 13,281 \\
\hline No IADL & 4.6 & 1.7 & 0.4 & 0.1 & 0.0 & 16,164 \\
\hline Total & $\mathbf{6 . 4}$ & $\mathbf{2 . 7}$ & $\mathbf{0 . 9}$ & $\mathbf{0 . 4}$ & $\mathbf{0 . 1}$ & $\mathbf{3 1 , 4 6 4}$
\end{tabular}

Table 2 depicts the proportion of the number of geriatric impairment by selected socioeconomic and health characteristics. Almost 90 percent of the elderly population do not have any impairment. Around 6.4 percent of the elderly reported at least one impairment, 2.7 percent reported at least two impairment, and 1.4 percent of the elderly reported three or more than three impairment. The proportion of 3 or more than three impairment was higher among elderly aged 70+ years, female elderly, never-married elderly, rural elderly, not working elderly, and elderly who reported poor self-reported health and severe ADL and IADL impairment. Almost 7 percent of elderly who had severe ADL and IADL impairment reported three or more geriatric impairment. 
Table 2

Proportion of number of geriatric impairment/s by selected socio-economic and health characteristics in India

$\begin{array}{lllll}0 & 1 & 2 & \geq 3 & \text { Total }(\mathrm{N})\end{array}$

\section{Age}

60-69

91.1

5.6

2.4

0.9

18,410

$70+$

87.5

7.5

3.0

2.0

13,054

Sex

Male

89.6

6.8

2.4

1.2

14,931

Female

89.7

6.0

2.8

1.5

16,533

\section{Marital Status}

Currently married

$90.7 \quad 5.8$

2.4

1.1

19,536

Never Married

73.8

19.9

3.8

2.4

225

Divorced/Separated/Deserted

88.1

7.1

3.0

1.8

11,703

\section{Education}

\begin{tabular}{l} 
No education \\
Below primary \\
Primary \\
\hline Secondary \\
\hline Higher \\
Place of residence \\
\hline
\end{tabular}

Rural

Urban

\begin{tabular}{lllll}
88.5 & 7.0 & 3.1 & 1.4 & 17,782 \\
\hline 89.0 & 6.5 & 2.7 & 1.8 & 3,598 \\
\hline 89.5 & 6.8 & 2.3 & 1.4 & 3,520 \\
92.8 & 4.7 & 1.5 & 1.0 & 5,285 \\
\hline 94.3 & 2.9 & 2.1 & 0.6 & 1,278
\end{tabular}

\section{Living arrangements}

\begin{tabular}{llllll}
\hline Living alone & 87.1 & 8.5 & 3.2 & 1.2 & 1,787 \\
\hline With spouse & 90.8 & 5.8 & 2.4 & 1.0 & 19,176 \\
\hline With others & 87.9 & 7.1 & 2.9 & 2.1 & 10,501
\end{tabular}

\section{Currently working}

\begin{tabular}{llllll} 
Yes & 92.4 & 4.7 & 2.2 & 0.7 & 9,483 \\
\hline No & 87.5 & 7.7 & 3.1 & 1.8 & 13,197 \\
\hline Wealth Index & & & & & \\
\hline Poorest & 89.2 & 7.1 & 2.6 & 1.1 & 6,829 \\
\hline Poorer & 88.9 & 6.6 & 3.1 & 1.4 & 6,831 \\
\hline Middle & 90.4 & 5.8 & 2.3 & 1.6 & 6,590 \\
\hline & Page $8 / 18$ & & & &
\end{tabular}




\begin{tabular}{llllll} 
Richer & 89.7 & 6.5 & 2.5 & 1.3 & 6,038 \\
\hline Richest & 90.1 & 5.7 & 2.8 & 1.4 & 5,175
\end{tabular}

Self-rated health

\begin{tabular}{llllll}
\hline Poor & 82.7 & 9.8 & 4.8 & 2.7 & 4,630 \\
\hline Good & 91.9 & 5.4 & 2.0 & 0.7 & 26,181
\end{tabular}

ADL disability

\begin{tabular}{llllll}
\hline Severe ADL & 67.7 & 15.6 & 9.6 & 7.1 & 999 \\
\hline Moderate ADL & 82.7 & 10.4 & 4.4 & 2.5 & 6,045 \\
\hline No ADL & 92.2 & 5.1 & 2.0 & 0.8 & 24,291 \\
\hline
\end{tabular}

\section{IADL disability}

\begin{tabular}{llllll}
\hline Severe IADL & 71.9 & 13.6 & 7.6 & 7.0 & 1,859 \\
\hline Moderate IADL & 87.4 & 7.7 & 3.2 & 1.7 & 13,281 \\
\hline No IADL & 93.3 & 4.6 & 1.7 & 0.4 & 16,164 \\
\hline Total & $\mathbf{8 9 . 6}$ & $\mathbf{6 . 4}$ & $\mathbf{2 . 7}$ & $\mathbf{1 . 4}$ & $\mathbf{3 1 , 3 0 4}$
\end{tabular}

Table 3 depicts the result of logistic regression of geriatric impairment by selected socioeconomic and health characteristics. In the unadjusted odds model, increasing age was a significant predictor of geriatric impairment. Elderly aged $70+$ were 1.46 times $(O R=1.46 ; C . I .=1.27-1.69)$ more likely to report geriatric impairment than elderly aged 60-69 years. In the adjusted model, female elderly were less likely $(\mathrm{OR}=0.81 ; \mathrm{C} . \mathrm{I} .=0.68-0.97)$ to report geriatric impairment than male elderly. In both adjusted and unadjusted models, the never-married elderly reported higher odds of reporting geriatric impairment than those who were married. Never-married elderly were 2.68 times (OR=2.46; C.I. 1.23-5.87) more likely to report geriatric impairment than married elderly. In the adjusted model, elderly with higher education were less likely $(\mathrm{OR}=0.57 ; \mathrm{C} . \mathrm{I} .=0.32-1.02)$ to report geriatric impairment than uneducated elderly. Elderly not working currently had higher odds of reporting geriatric impairment $(\mathrm{OR}=1.23 ; \mathrm{C} . \mathrm{I}=1.06-1.43)$ than the working elderly. Elderly who had good self-rated health (OR=0.59; C.I. 0.50-0.70), had no ADL (OR=0.38; C.I.=0.25-0.56), and no IADL $(\mathrm{OR}=0.46 ; \mathrm{C} . \mathrm{I}=0.33-0.65)$ reported lower odds of geriatric impairment than their respective counterparts. 
Table 3

logistic regression of geriatric impairments (Unadjusted and adjusted) by selected socio-economic and health characteristics in India

\section{Unadjusted odds ratio $\quad \mathrm{Cl}$ at $95 \% \quad$ Adjusted odds ratio $\quad \mathrm{Cl}$ at $95 \%$}

\section{Age}

60-69

$70+$

$1.46^{* * *}$

$1.27-1.69 \quad 0.93$

$0.80-1.08$

Sex

Male

Female

1.00

0.86-1.14 $0.81^{\text {** }}$

$0.68-0.97$

\section{Marital Status}

Currently married

Never Married

$3.46 * * \star$

2.23-5.38 2.68**

$1.23-5.87$

Divorced/Separated/Deserted

$1.32 * \star *$

$1.14-1.53 \quad 1.58$

$0.86-2.86$

\section{Education}

No education

\begin{tabular}{lllll} 
Below primary & 0.95 & $0.75-1.18$ & 1.00 & $0.77-1.27$ \\
\hline Primary & 0.90 & $0.74-1.10$ & 0.97 & $0.76-1.23$ \\
\hline Secondary & $0.59 * \star *$ & $0.49-0.72$ & 0.80 & $0.62-1.02$ \\
\hline Higher & $0.46 * \star *$ & $0.30-0.71$ & $0.57 * \star$ & $0.32-1.02$
\end{tabular}

\section{Place of residence}

Rural

Urban

$0.81^{\star *}$

$0.66-1.00 \quad 0.93$

$0.73-1.16$

\section{Living arrangements}

Living alone

With spouse

$0.68 * \star \star$

0.54-0.85

1.28

$0.57-2.45$

With others

0.93

0.72-1.19

$0.75^{\star \star}$

0.56-0.99

\section{Currently working}

Yes

No

$1.75^{\star \star \star}$

$1.52-2.01 \quad 1.23$ *

$1.06-1.43$

Wealth Index

Poorest

Poorer

1.03

$0.82-1.28 \quad 0.99$

$0.81-1.21$ 
Middle

0.88

0.72-1.07

1.02

0.82-1.25

Richer

0.95

0.76-1.17

1.10

0.85-1.41

Richest

0.91

0.74-1.10

$1.22^{\star *}$

0.98-1.52

\section{Self-rated health}

\section{Poor}

Good

$0.41^{\star \star *}$

$0.36-0.48$

$0.59 * \star \star$

$0.50-0.70$

\section{ADL disability}

Severe ADL

\begin{tabular}{lllll} 
Moderate ADL & $0.43^{\star \star *}$ & $0.33-0.56$ & $0.65^{\star \star}$ & $0.44-0.96$ \\
\hline No ADL & $0.17 * \star *$ & $0.14-0.22$ & $0.38 * \star \star$ & $0.25-0.56$
\end{tabular}

\section{IADL disability}

Severe IADL

Moderate IADL

$0.36^{\star * *}$

$0.30-0.44$

0.84

$0.62-1.13$

No IADL

0.18 ***

0.14-0.22

$0.46 * * \star$

0.33-0.65

\section{Discussion:}

The overall prevalence of geriatric impairment estimated in the study was 10.4 percent; the specific impairment prevalence varies from 6.4 percent in physical impairment to 0.1 percent in speech impairment. The prevalence of hearing, vision, and cognitive impairment was $0.9 \%, 0.4 \%$, and $2.7 \%$, respectively. These figures are lower than other country prevalence of estimates on hearing and vision impairment [14], [33], [34] and cognitive impairment [35], [36]. The World Health Organization (WHO) estimates that approximately 360 million, or 5\% of the world's population, have at least a moderate hearing loss [37]. A study examining visual, hearing, walking, cognition, self-care, and communication impairment found an almost similar prevalence of impairment among the Malaysian elderly as in this study [38].

The study has demonstrated that higher age had a gradient of negative impact on the older adults, although for the unadjusted model. The results found that higher age is a risk factor for impairment among the elderly. Previous findings corroborated the above finding in the Indian context [39]. Higher age is associated with several co-morbidities, which may further aggravated impairment among them [40]. Female elderly were less likely to report impairment than their male counterparts. Previous literature has found mixed evidence. Few studies noted a higher risk of impairments in the male elderly [41], and other few noted an otherwise association [42]. Lower impairments among females could be attributed to various factors, notably higher treatment-seeking [43]. Risk-taking and reluctance to seek and comply with medical treatment among men could be another explanation of higher impairments among men [43]. These gender differences appear to align with various literature, which proposes that men report fatal and functionally-related disabilities more frequently, which often warrant hospitalization, specialty care, and emergency services use than women [44], [45].

The marital status of the elderly was another significant predictor of impairments. The study found that the nevermarried elderly were more likely to report impairments than their married counterparts. Previous studies also noted the 
same association [46]. Married elderly are supposed to get support from their spouse, leading to better health and lower impairments. The pathway through which marital union explains the reduced risk of impairments among the elderly includes security and cohesion, which states that marriage may provide a sense of cohesion, security, and coping resources, leading to improved quality of life and thus reducing the risk of impairments [47]. Our study revealed that older people who were at lower risk for disabilities were those who had higher education. Previous studies agree with this finding [38], [48]. A study in rural India has noticed the same relationship between education level and impairment among the elderly [49]. Low education level is closely associated with low-income status, which might become a barrier for health services utilization, leading to geriatric impairment [38].

The results significantly noted that working elderly had a lower risk of impairments than non-working elderly. Previous research corroborated this finding [50]. There are several pathways explaining the reduced risk of impairments among the working elderly, including the cognitive research hypothesis. The cognitive research hypothesis suggests that occupational attainment facilitates coping mechanisms, reducing the likelihood of impairments, specifically cognitive impairments [50]. The results found poor self-rated health as a risk factor of higher impairments among the elderly. Previously available research noticed that good self-rated health is a strong predictor of lower disability and impairments among the elderly, specifically cognitive and physical impairments [47]. The indication is that those who reported good self-rated health are more likely to link with better health characteristics, including reduced chances of chronic diseases and mental health, leading to less risk of impairments. The study noticed that severe ADL and IADL were associated with a higher risk of geriatric impairments among the elderly. However, the cross-sectional nature of data limits our understanding of causality appropriately. A study has noticed an inverse relationship where geriatric impairments were associated with poor ADL and IADL [51]. In line with this study finding, previous research substantiated that severe ADL and IADL affect physical and cognitive impairments among the elderly [52].

\section{Strengths And Limitations Of The Study:}

The study has potential noteworthy limitations. The prevalence of impairments might be under-estimated as they were self-reported. A study noted that more than one-third of people with impairment in vision or hearing were identified clinically but did not report their functional limitations [53]. Reverse causality cannot be ignored as the data is crosssectional, preventing the identification of causal relationships between covariates and impairment. Despite the above limitations, the study has certain strengths too. The use of a large nationally representative sample in this survey provides valid and reliable estimates of geriatric impairment in India.

\section{Conclusion:}

The LASI survey provides reliable and comparable data on geriatric impairment in India. Our findings indicated that males, being never-married, currently working, poor self-rated health, severe ADL, and severe IADL are some of the risk factors for impairment among the elderly in India. Findings from this study accentuated the need for strengthening the health services targeting older people, specifically those who reported poor self-rated health, severe ADL, and IADL. Also, there is a need for impairment-specific interventions. Early identification of hearing and vision loss could be an effective mechanism to reduce the burden of sensory impairment among the elderly. The systematic screening for hearing and vision loss detection could be promoted in India's primary health care (PHC) centers. There is a need to building partnerships to develop effective programs tackling impairment among the elderly. Launching programs that provide education for older adults to elicit potential health benefits may reduce impairment progression.

\section{Abbreviations}


ADL: Activity of Daily Living

CEBs: Census Enumeration Blocks

Cl: Confidence Interval

IADL: Instrumental Activity of Daily Living

LASI: Longitudinal Ageing Study in India

OR: Odds Ratio

WHO: World Health Organization

\section{Declarations}

\section{Ethics approval and consent to participate:}

The authors were not involved in data collection process and therefore they did not require any ethical approval or consent to participate. The study used LASI survey data and LASI data is secondary in nature. The data is freely available on request and survey agencies that conducted the field survey for the data collection have collected a prior consent from the respondent. The ethical clearance was provided by Indian Council of Medical Research (ICMR), India. The survey agencies that collected data followed all the protocols. To maximize the cooperation of the sampled HHs and individuals, participants were provided with information brochures explaining the purpose of the survey, ways of protecting their privacy, and the safety of the health assessments as part of the ethics protocols. As per ethics protocols, consent forms were administered to each $\mathrm{HH}$ and age-eligible individual. In accordance with Human Subjects Protection, four consent forms were used in the LASI: Household Informed Consent, Individual Informed Consent, Consent for Blood Samples Collection for Storage and Future Use (DBS), and Proxy Consent. For each survey participant, the study protocol was described and the steps of each biomarker test were demonstrated by the trained health investigators. Participant's consent (signed/oral) was obtained for the interviews. Since, the survey obtained either signed or oral consent, it was feasible for each participant to provide his/her consent.

\section{Consent for publication:}

Not applicable

\section{Availability of data and materials:}

The datasets generated and/or analysed during the current study are available with the International Institute for Population Sciences, Mumbai, India repository and could be accessed from the following link: https://iipsindia.ac.in/sites/default/files/LASI_DataRequestForm_0.pdf. Those who wish to download the data have to follow the above link. This link leads to a data request form designed by International Institute for Population Sciences. After completing the form, it should be mailed to: datacenter@iips.net for further processing. After successfully sending the mail, individual will receive the data in a reasonable time.

\section{Competing Interest:}


The authors declare that they have no competing interests.

\section{Funding:}

Authors did not received any funding to carry out this research.

\section{Author's Contribution:}

The concept was drafted by SK and SC. SK contributed to the analysis design. SC advised on the paper and assisted in paper conceptualization. SC, RP, and DJS contributed in the comprehensive writing of the article. All authors read and approved the final manuscript.

\section{Acknowledgements:}

Not applicable

\section{References}

1. S. Chauhan and P. Arokiasamy, "India's demographic dividend: state-wise perspective," Journal of Social and Economic Development, vol. 20, no. 1, pp. 1-23, 2018.

2. WHO, "Ageing and health," World Health Organization, 2018. Accessed: May 21, 2021. [Online]. Available: https://www.who.int/news-room/fact-sheets/detail/ageing-and-health

3. S. Srivastava, S. Chauhan, and R. Patel, "Socio-economic inequalities in the prevalence of poor self-rated health among older adults in India from 2004 to 2014: A decomposition analysis," Ageing International, pp. 1-18, 2020.

4. A. Agarwal, A. Lubet, E. Mitgang, S. Mohanty, and D. E. Bloom, "Population aging in India: Facts, issues, and options," in Population change and impacts in Asia and the Pacific, Springer, 2020, pp. 289-311.

5. R. Patel, S. Chauhan, D. Chaurasiya, S. Kumar, and B. Paswan, "Role and Impact of Social Capital on Health of Older Adult in India," Indian Journal of Social Research, vol. 60, no. 2, pp. 279-305, 2019.

6. R. Patel, S. P. Marbaniang, S. Srivastava, P. Kumar, S. Chauhan, and D. J. Simon, "Gender differential in low psychological health and low subjective well-being among older adults in India: With special focus on childless older adults," Plos one, vol. 16, no. 3, p. e0247943, 2021.

7. R. Patel and S. Chauhan, "Gender differential in health care utilisation in India," Clinical Epidemiology and Global Health, vol. 8, no. 2, pp. 526-530, 2020.

8. G. K. Ingle and A. Nath, "Geriatric health in India: Concerns and solutions," Indian journal of community medicine: official publication of Indian Association of Preventive \& Social Medicine, vol. 33, no. 4, p. 214, 2008.

9. M. Giri, T. Chen, W. Yu, and Y. Lü, "Prevalence and correlates of cognitive impairment and depression among elderly people in the world's fastest growing city, Chongqing, People's Republic of China," Clinical interventions in aging, vol. 11, p. 1091, 2016.

10. S. Gupta, R. Yadav, and A. K. Malhotra, "Assessment of physical disability using Barthel index among elderly of rural areas of district Jhansi (UP), India," Journal of family medicine and primary care, vol. 5, no. 4, p. 853, 2016.

11. A. Kasthuri, "Visual and hearing impairment among rural elderly of south India: a community-based study.," Geriatrics \& gerontology international, vol. 12, no. 1, pp. 116-122, 2011. 
12. Z. A. Khan, C. Singh, and T. Khan, "Correlates of physical disability in the elderly population of rural North India (Haryana)," Journal of family \& community medicine, vol. 25, no. 3, p. 199, 2018.

13. P. Sengupta, A. I. Benjamin, Y. Singh, and A. Grover, "Prevalence and correlates of cognitive impairment in a north Indian elderly population," WHO South-East Asia journal of public health, vol. 3, no. 2, pp. 135-143, 2014.

14. M. A. Rooth, "The Prevalence and Impact of Vision and Hearing Loss in the Elderly," North Carolina Medical Journal, vol. 78, no. 2, pp. 118-120, Mar. 2017, doi: 10.18043/ncm.78.2.118.

15. Z. Yin et al., "Dietary diversity and cognitive function among elderly people: A population-based study," The journal of nutrition, health \& aging, vol. 21, no. 10, pp. 1089-1094, 2017.

16. V. Heyl and H.-W. Wahl, "Managing daily life with age-related sensory loss: cognitive resources gain in importance.," Psychology and aging, vol. 27, no. 2, p. 510, 2012.

17. V. Taler and N. A. Phillips, "Language performance in Alzheimer's disease and mild cognitive impairment: a comparative review," J Clin Exp Neuropsychol, vol. 30, no. 5, pp. 501-556, Jul. 2008, doi: $10.1080 / 13803390701550128$.

18. S. D. Lambert et al., "Impact of informal caregiving on older adults' physical and mental health in low-income and middle-income countries: a cross-sectional, secondary analysis based on the WHO's Study on global AGEing and adult health (SAGE)," BMJ open, vol. 7, no. 11, p. e017236, 2017.

19. S. Srivastava, T. Anwar, R. Patel, and S. Chauhan, "Dynamics of chronic diseases in metro and non-metro regions of India: evidence from India Human Development Survey I and II," International Journal, vol. 6, no. 8, p. $322,2020$.

20. M. Verma, S. Grover, T. Singh, N. Dahiya, and R. Nehra, "Screening for cognitive impairment among the elderly attending the noncommunicable diseases clinics in a rural area of Punjab, North India," Asian journal of psychiatry, vol. 50, p. 102001, 2020.

21. M. Pilania et al., "Prevalence of depression among the elderly (60 years and above) population in India, 19972016: a systematic review and meta-analysis," BMC public health, vol. 19, no. 1, pp. 1-18, 2019.

22. V. Reddy, "Mental health issues and challenges in India: A review," International Journal of Social Sciences Management and Entrepreneurship (IJSSME), vol. 3, no. 2, 2019.

23. S. Srivastava et al., "Older adults' psychological and subjective well-being as a function of household decision making role: Evidence from cross-sectional survey in India," Clinical Epidemiology and Global Health, vol. 10, p. 100676, 2021.

24. G. Bishwajit, D. P. O'Leary, S. Ghosh, S. Yaya, T. Shangfeng, and Z. Feng, "Physical inactivity and self-reported depression among middle-and older-aged population in South Asia: World health survey," BMC geriatrics, vol. 17, no. 1, pp. 1-8, 2017.

25. T. Bright, I. Mactaggart, H. Kuper, G. V. Murthy, and S. Polack, "Prevalence of Hearing Impairment in Mahabubnagar District, Telangana State, India," Ear and hearing, vol. 40, no. 1, pp. 204-212, 2019.

26. S. Marmamula et al., "Prevalence and risk factors for visual impairment among elderly residents in "homes for the aged'in India: the Hyderabad Ocular Morbidity in Elderly Study (HOMES)," British Journal of Ophthalmology, vol. 105 , no. 1, pp. 32-36, 2021.

27. D. Vignesh, N. Gupta, M. Kalaivani, A. K. Goswami, B. Nongkynrih, and S. K. Gupta, "Prevalence of visual impairment and its association with vision-related quality of life among elderly persons in a resettlement colony of Delhi," Journal of family medicine and primary care, vol. 8, no. 4, p. 1432, 2019.

28. S. Oommen and G. L. Jose, “Communication Aiding System for People with Speech Impairment," International Journal of Engineering Research \& Technology, vol. 3, no. 10, pp. 1045-1048, 2014. 
29. Y. Krishnamoorthy, G. Sarveswaran, K. Sivaranjini, M. Sakthivel, M. G. Majella, and S. G. Kumar, "Association between indoor air pollution and cognitive impairment among adults in rural Puducherry, South India," Journal of neurosciences in rural practice, vol. 9, no. 4, p. 529, 2018.

30. D. Mohan, T. lype, S. Varghese, A. Usha, and M. Mohan, "A cross-sectional study to assess prevalence and factors associated with mild cognitive impairment among older adults in an urban area of Kerala, South India," BMJ open, vol. 9, no. 3, p. e025473, 2019.

31. S. Katz, "The index of ADL: a standardized measure of biological and psychosocial function," Jama, vol. 185, pp. 914-919, 1963.

32. M. P. Lawton and E. M. Brody, "Assessment of older people: self-maintaining and instrumental activities of daily living," The gerontologist, vol. 9, no. 3_Part_1, pp. 179-186, 1969.

33. J. C. Lee, A. N. Danker, Y. H. Wong, and M. Y. Lim, "Hearing Loss amongst the Elderly in a Southeast Asian Population - A Community- based Study," vol. 46, no. 4, p. 10, 2017.

34. A. B. Servidoni, L. de O. Conterno, A. B. Servidoni, and L. de O. Conterno, "Hearing Loss in the Elderly: Is the Hearing Handicap Inventory for the Elderly - Screening Version Effective in Diagnosis When Compared to the Audiometric Test?," International Archives of Otorhinolaryngology, vol. 22, no. 1, pp. 1-8, Jan. 2018, doi: 10.1055/s-00371601427.

35. M. Alkhunizan, A. Alkhenizan, and L. Basudan, "Prevalence of Mild Cognitive Impairment and Dementia in Saudi Arabia: A Community-Based Study," DEE, vol. 8, no. 1, pp. 98-103, 2018, doi: 10.1159/000487231.

36. L. Ren et al., "Investigation of the prevalence of Cognitive Impairment and its risk factors within the elderly population in Shanghai, China," Scientific Reports, vol. 8, no. 1, Art. no. 1, Feb. 2018, doi: 10.1038/s41598-01821983-w.

37. WHO, "Deafness and hearing loss," World Health Organization, 2021. Accessed: May 21, 2021. [Online]. Available: https://www.who.int/news-room/fact-sheets/detail/deafness-and-hearing-loss

38. N. A. Ahmad et al., "Prevalence and determinants of disability among adults in Malaysia: results from the National Health and Morbidity Survey (NHMS) 2015," BMC Public Health, vol. 17, no. 1, p. 756, Sep. 2017, doi: 10.1186/s12889-017-4793-7.

39. R. Gong et al., "Hearing loss prevalence and risk factors among older adults in China," International Journal of Audiology, vol. 57, no. 5, pp. 354-359, May 2018, doi: 10.1080/14992027.2017.1423404.

40. M. A. Garcia and A. M. Reyes, "Prevalence and Trends in Morbidity and Disability Among Older Mexican Americans in the Southwestern United States, 1993-2013," Res Aging, vol. 40, no. 4, pp. 311-339, Apr. 2018, doi: 10.1177/0164027517697800.

41. L. Wang, T. Tian, and A. D. N. Initiative, "Gender Differences in Elderly With Subjective Cognitive Decline," Front. Aging Neurosci., vol. 10, 2018, doi: 10.3389/fnagi.2018.00166.

42. D. Sohn et al., "Sex Differences in Cognitive Decline in Subjects with High Likelihood of Mild Cognitive Impairment due to Alzheimer's disease," Scientific Reports, vol. 8, no. 1, Art. no. 1, May 2018, doi: 10.1038/s41598-018-25377w.

43. A. Oksuzyan, K. Juel, J. W. Vaupel, and K. Christensen, "Men: good health and high mortality. Sex differences in health and aging," Aging Clin Exp Res, vol. 20, no. 2, pp. 91-102, Apr. 2008, doi: 10.1007/BF03324754.

44. K. A. Cameron, J. Song, L. M. Manheim, and D. D. Dunlop, "Gender Disparities in Health and Healthcare Use Among Older Adults," Journal of Women's Health, vol. 19, no. 9, pp. 1643-1650, Aug. 2010, doi: 10.1089/jwh.2009.1701. 
45. Y. Wang, K. Hunt, I. Nazareth, N. Freemantle, and I. Petersen, "Do men consult less than women? An analysis of routinely collected UK general practice data," BMJ Open, vol. 3, no. 8, p. e003320, Aug. 2013, doi: 10.1136/bmjopen-2013-003320.

46. Z. Zhou et al., "A Longitudinal Analysis of the Association Between Living Arrangements and Health Among Older Adults in China," Res Aging, vol. 40, no. 1, pp. 72-97, Jan. 2018, doi: 10.1177/0164027516680854.

47. R. M. Gyasi and D. R. Phillips, "Gender, self-rated health and functional decline among community-dwelling older adults," Archives of Gerontology and Geriatrics, vol. 77, pp. 174-183, Jul. 2018, doi:

10.1016/j.archger.2018.05.010.

48. et al., "Limited formal education is strongly associated with lower cognitive status, functional disability and frailty status in older adults," Dementia \& Neuropsychologia, vol. 13, no. 2, pp. 216-224, Jun. 2019, doi: 10.1590/198057642018dn13-020011.

49. P. Gupta, K. Mani, S. K. Rai, B. Nongkynrih, and S. K. Gupta, "Functional disability among elderly persons in a rural area of Haryana," Indian Journal of Public Health, vol. 58, no. 1, p. 11, Jan. 2014, doi: 10.4103/0019-557X.128155.

50. R. M. Patel and U. S. Singh, "Prevalence study of cognitive impairment and its associated sociodemographic variables using mini-mental status examination among elderly population residing in field practice areas of a medical college," Indian journal of community medicine: official publication of Indian Association of Preventive \& Social Medicine, vol. 43, no. 2, p. 113, 2018.

51. S. F. Nourbakhsh, R. Fadayevatan, M. Alizadeh-Khoei, and F. Sharifi, "Determining the status of activity of daily living (ADL) and instrumental activity of daily living (IADL) in healthy and cognitive impaired elderlies," Jorjani Biomedicine Journal, vol. 5, no. 2, pp. 63-77, Oct. 2017.

52. R. J. Gobbens, "Associations of ADL and IADL disability with physical and mental dimensions of quality of life in people aged 75 years and older," PeerJ, vol. 6, p. e5425, Aug. 2018, doi: 10.7717/peerj.5425.

53. I. Mactaggart, H. Kuper, G. V. S. Murthy, J. Oye, and S. Polack, "Measuring Disability in Population Based Surveys: The Interrelationship between Clinical Impairments and Reported Functional Limitations in Cameroon and India," PLOS ONE, vol. 11, no. 10, p. e0164470, Oct. 2016, doi: 10.1371/journal.pone.0164470.

\section{Figures}

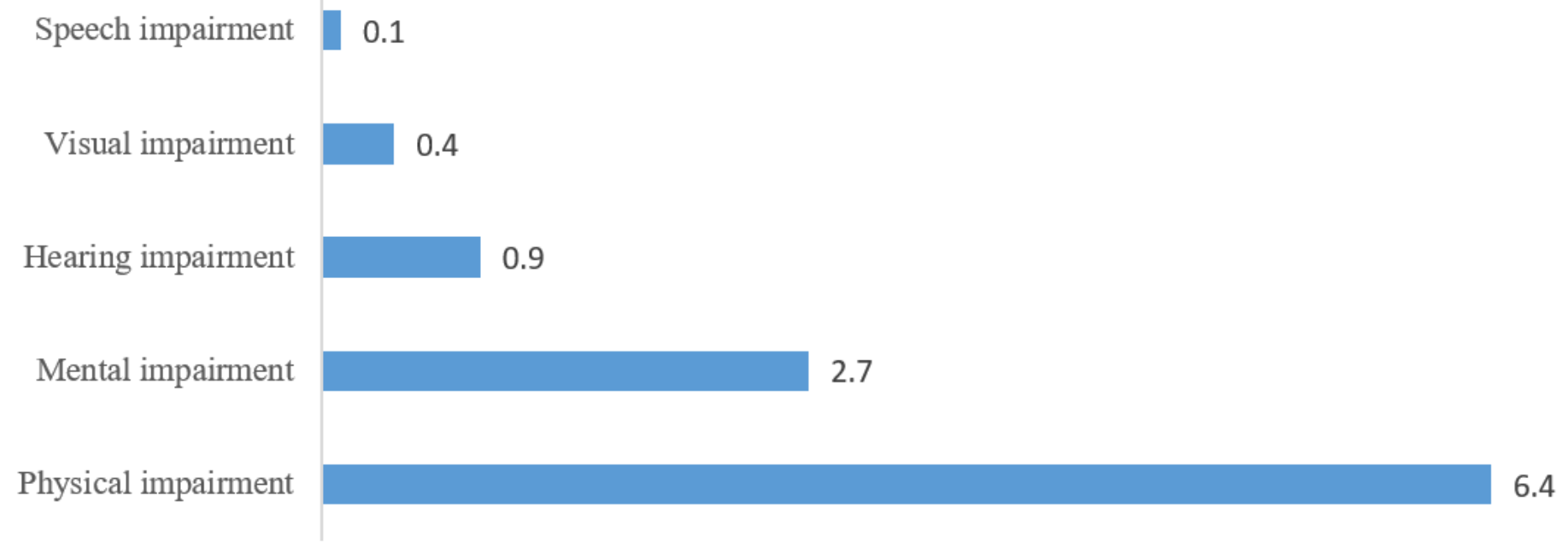

Figure 1

Page $17 / 18$ 
Title: Types of geriatric impairments among older adults in India Legends: Types of geriatric impairments 